\title{
Clinical subtypes of obsessive-compulsive disorder based on the presence of checking and washing compulsions
}

\author{
Subtipos clínicos do transtorno obsessivo- \\ compulsivo com base na presença de compulsões de \\ checagem e lavagem
}

Abstract Leonardo F Fontenelle, ${ }^{1,2}$ Mauro V Mendlowicz, ${ }^{3,4}$

Objective: We aimed at examining the utility of checking and washing compulsions as markers of valid subtypes of obsessive-compulsive disorder (OCD). Methods: One hundred and six patients with obsessive-compulsive disorder were evaluated with a socio-demographic and clinical questionnaire, the Structured Clinical Interview for DSM-IV, the Yale-Brown Obsessive-Compulsive Scale, the Clinical Global Impression, the Beck Depression Inventory, the Hamilton Rating Scale for Depression, and the Global Assessment of Functioning. These individuals were allocated in one of four subgroups [checkers (OCD-Ch; $n=20)$, washers (OCD-Wa; $n=13)$, checkers and washers (OCD$C W ; n=48)$, and non-checkers and non-washers (OCD non-CW =25)] on the basis of the presence and the clinical relevance of checking and/or washing compulsive behaviors across their lifetime. Socio-demographic and clinical variables were compared and contrasted between the groups by means of ANOVA followed by post-hoc Least Significant Difference or Dunnett's tests for continuous variables and chi-square tests followed by partitioned chi-square tests for categorical variables. Results: OCD-Ch and OCD-Wa did not differ on most demographic and clinical features, the only exception being the number of different types of obsessions, which were significantly higher in the former group. The OCD-CW group was more likely to exhibit an insidious onset of obsessive-compulsive symptoms, to manifest itself as a mixed subtype of obsessive-compulsive disorder and to display obsessions with contamination themes. On the other hand, the OCD nonCW group was more likely to exhibit an acute onset, a shorter duration of illness, obsessions with religious themes, an episodic course, and less severe obsessive-compulsive symptoms. Conclusions: In our sample, the probing of the presence of checking and/or washing compulsions has provided significant empirical support to establish valid subtypes of obsessive-compulsive disorder.

Keywords: Obsessive-compulsive disorder; Compulsive behavior; Checking; Washing

\section{Resumo}

Objetivo: Nós investigamos a utilidade das compulsões de verificação e de lavagem como marcadores de subtipos válidos do transtorno obsessivo-compulsivo (TOC). Métodos: Cento e seis pacientes com transtorno obsessivo-compulsivo foram avaliados com um questionário sociodemográfico e clínico e com a entrevista clínica estruturada para o DSM-IV, a escala de sintomas obsessivo-compulsivos de YaleBrown, a escala de impressão clínica global, o inventário de depressão de Beck, a escala para avaliação de depressão de Hamilton e a avaliação global de funcionamento. Estes indivíduos foram incluídos em um dos seguintes subgrupos: verificadores (TOC-Ver; $n=20$ ), lavadores (TOC-Lav; $n=13$ ), verificadores e lavadores (TOC-VL; $n=48$ ) e não-verificadores e não-lavadores (TOC-NVL = 25). Esta classificação foi realizada com base na presença e relevância clínica de compulsões de verificação e de lavagem ao longo da vida dos pacientes. As variáveis sociodemográficas e clínicas foram comparadas e contrastadas entre os subgrupos através de uma ANOVA seguida pelos testes $L S D$ ou Dunnett para variáveis contínuas e do teste do qui-quadrado seguido pelo qui-quadrado particionado para variáveis categóricas. Resultados: Os pacientes com TOC-Ver e os pacientes com TOC-Lav não diferiram significativamente entre si na maioria das variáveis incluídas no estudo, com exceção do número de diferentes tipos de obsessões, significativamente maior nos primeiros. Os pacientes com TOC-VL exibiram, com maior freqüência, um início insidioso, o subtipo misto de TOC segundo a CID-10 e obsessões de contaminação. Pacientes com TOC-NVL apresentaram, com maior freqüência, um início súbito, menor duração de sintomas, obsessões de conteúdo religioso, curso episódico e sintomas obsessivo-compulsivos menos graves. Conclusões: A investigação quanto à presença de compulsões de verificação e lavagem sugeriu que estes sintomas podem contribuir para validar subtipos de transtorno obsessivo-compulsivo.

Descritores: Transtorno obsessivo-compulsivo; Comportamento compulsivo; Verificação; Lavagem

\footnotetext{
1 Institute of Psychiatry, Universidade Federal do Rio de Janeiro (UFRJ), Rio de Janeiro (RJ), Brazil

2 Anxiety and Depression Research Program, Institute of Psychiatry, Universidade Federal do Rio de Janeiro (UFRJ), Rio de Janeiro (RJ), Brazil

3 Department of Psychiatry and Mental Health, Universidade Federal Fluminense (UFF), Rio de Janeiro (RJ), Brazil

4 Ethics Research Program, Institute of Psychiatry, Universidade Federal do Rio de Janeiro (UFRJ), Rio de Janeiro (RJ), Brazil

5 Department of Psychiatry and Legal Medicine, Institute of Psychiatry, Universidade Federal do Rio de Janeiro (UFRJ), Rio de Janeiro (RJ), Brazil

6 Director of the Institute of Psychiatry, Universidade Federal do Rio de Janeiro (UFRJ), Rio de Janeiro (RJ), Brazil
}

Financing: Conselho Nacional de Desenvolvimento Científico e Tecnológico (CNPq) nr. 141517/00-0

Conflicts of interests: None

Submitted: 21 November 2004

Accepted: 1 March 2005

\section{Correspondence}

Leonardo F Fontenelle

Rua Lopes Trovão, 88, apt 1501, Bloco A - Icaraí

24220-071 Niterói, RJ, Brazil

Phone: (55 21) 2710-7857; Fax: (55 21) 2710-5161

E-mail: Ifontenelle@gmail.com 


\section{Introduction}

Several studies suggest that obsessive-compulsive disorder (OCD) is in fact a set of related syndromes that, despite phenomenological similarities, can be differentiated according to their socio-demographic characteristics, ${ }^{1-3}$ age at onset, ${ }^{4-6}$ pattern of comorbidity, ${ }^{7}$ family history, ${ }^{8}$ response to drug treatment, ${ }^{9-10}$ and neurobiological underpinnings. ${ }^{11}$ The identification of homogeneous subgroups of patients with OCD is an important step in the quest for identifying specific pathophysiological mechanisms and for developing effective treatment strategies. ${ }^{12}$

Checking and washing compulsions are the most common forms of ritualistic behavior in clinical samples of OCD from several different countries. ${ }^{13}$ Although an individual with OCD may exhibit both behaviors, some authors have argued that, in the vast majority of cases, one type of ritual usually predominates, permitting the patient to be classified as a 'checker' or 'washer'. ${ }^{14}$ Indeed, several studies suggest that checking and washing compulsions tend to load on different factors ${ }^{15-17}$ or clusters. ${ }^{18}$ Despite all the recent interest in the clinical and biological heterogeneity of OCD, only a few studies have investigated the utility of washing and checking compulsions as markers of valid subtypes of this disorder. ${ }^{14,19-23}$

Steketee et al have found, for instance, that OCD checkers and washers were similar on the basis of age, gender, symptom duration, marital status, religion, and socioeconomic levels. ${ }^{14}$

However, regarding clinical aspects, OCD washers' fears were triggered by environmental stimuli more often than OCD checkers', whose fears tended to focus more on concern with preventing future harm. More fears and greater passive avoidance were exhibited by washers than by checkers. Checkers more frequently perceived their mothers as meticulous and demanding than did washers.

In contrast, Khanna et al have reported that OCD checkers were more often young, single, male, and Christian, and more likely to have an insidious onset of OCD. On the other hand, OCD washers were more likely to be female and housewives, less likely to be postgraduates or in skilled and professional vocations, and more likely to have the onset of OCD after marriage. ${ }^{21}$ In this study, the mixed group (individuals with simultaneous checking and washing compulsions) resembled checkers, except for an excess of females.

In another investigation, Horesh et al have found that OCD washers were 32 times more likely than OCD checkers to display DSM-III-R personality disorders. These authors were unable, however, to identify any specific association between a given personality disorder and the predominance of washing compulsions. ${ }^{20}$

In a positron emission tomography study, increased regional blood flow was reported in the striatum of OCD checkers, and in the anterior cingulate and orbitofrontal cortex of OCD washers. ${ }^{24}$ These patients, however, were examined while performing a continuous performance task, rather than during the perception of checking or washing-relevant stimuli. In contrast, in a study with functional magnetic resonance imaging, Phillips et al found that only OCD washers perceived washing-related pictures as disgusting and activated brain areas involved in disgust perception (i.e., insula and visual regions). ${ }^{23}$

From the therapeutic standpoint, while the presence of washing compulsions was already linked to worse treatment response to serotonin reuptake inhibitors in patients with $O C D, 25-26$ checking compulsions were associated to an inferior response to exposure and ritual prevention therapy in most ${ }^{27-28}$ but not all ${ }^{29}$ studies.
Most of the previous investigators classified patients with OCD as checkers and/or washers on the basis of their manifest symptom phenotype, especially the patients' major compulsive behavior at the moment of the assessment. Nonetheless, OCD is characterized by symptoms which tend to shift in quality over time, i.e., checkers may become washers and vice-versa. ${ }^{30}$ Therefore, Matsunaga et al, decided to allocate patients with OCD in a given subgroup according to their principal lifetime symptoms. Patients with any principal symptom other than checking and washing compulsions were excluded from their study. ${ }^{22}$ As a result, they did not find significant differences in clinical and psychopathological characteristics between pure lifetime checkers and pure lifetime washers. Surprisingly, subjects in the mixed checker-washer group differed from other subjects in a number of aspects including the level of insight, more severe psychopathology and global dysfunction. These authors argued that the mixed group may constitute a valid subgroup of OCD.

While the lifetime and principal symptoms rating method adopted by Matsunaga et al, may have generated results deemed more valid than those obtained in previous studies, ${ }^{20-}$ ${ }^{21}$ several checkers (or washers) with milder forms of washing (or checking) compulsions might have been mistakenly classified as pure checkers (or washers), thus lessening or obscuring more remarkable differences between these potential subtypes of OCD. ${ }^{22}$

In the present study, therefore, we investigated the utility of checking and washing compulsions as markers of valid subtypes of OCD by means of a different methodology. We decided to allocate patients with OCD in one of four subgroups (checkers, washers, checkers and washers, and non-checkers and non-washers) according to the presence of clinically significant lifetime checking and/or washing behaviors (which were not necessarily the principal symptoms presented by a given patient). We hypothesized that 1) OCD checkers and washers would differ from each other and 2) the combined group would differ from the other three groups on sociodemographic and clinical grounds.

\section{Methods}

\section{Patients}

Individuals with OCD were consecutively recruited for a naturalistic pharmacological trial by the Anxiety and Depression Research Program of the Institute of Psychiatry of the Universidade Federal do Rio de Janeiro (IPUB/UFRJ). Inclusion criteria comprised: 1) age between 17 and 65 years old; 2) having OCD as the most significant current psychiatric diagnosis; and 3 ) being capable of reading and filling out forms and questionnaires. Exclusion criteria were: 1) significant medical, neurological or endocrine disorders, 2) current alcohol or drug abuse, 3) psychosis, and 4) severe personality or 5) sexual disorders.

One hundred and eighteen consecutive patients with OCD were initially assessed. Twelve patients were not included in the study because they displayed comorbid disorders with greater clinical relevance and severity than their OCD: two male patients with antisocial personality disorder and alcohol and cocaine abuse; four male patients with paraphilias or paraphilia-related disorders; one male patient with alcohol, cocaine, and marijuana abuse; one female patient with borderline personality disorder; one male patient with paranoid personality disorder; one male patient with moderate mental retardation; one female patient with mild mental retardation 
and bipolar disorder; and one female patient with schizophrenia.

\section{Assessment}

One hundred and six volunteers with OCD were selected and had their diagnosis confirmed by a research psychiatrist (LF) using the Structured Clinical Interview for DSM-IV, patient version (SCID-I/P). ${ }^{31}$ All volunteers were assessed with regard to their socio-demographic and clinical characteristics, including age, gender, age at onset, mode of onset, course, subtype of OCD according to the International Classification of Diseases, $10^{\text {th }}$ edition (ICD-10) (obsessive type, compulsive type, and mixed type), ${ }^{32}$ and duration of illness. Initial assessment also included the Yale-Brown Obsessive-Compulsive Scale (Y-BOCS), ${ }^{33-34}$ the Clinical Global Impression (CGI), ${ }^{35}$ the Hamilton Depression Rating Scale-21 (HDRS-21), ${ }^{36}$ the Beck Depression Inventory (BDI), ${ }^{37}$ and the Global Assessment of Functioning (GAF). ${ }^{38}$

From the original pool of one hundred and six individuals, $80.4 \%$ were referred by clinicians, while the remaining $19.6 \%$ were recruited through advertisements in newspapers and word of mouth. Clinician-referred subjects did not have more severe OCD than self-referrals, as measured by initial Y-BOCS $(F=1.21$; $d f=99 ; p=.26)$ and CGI scores ( $F=.63 ; d f=98 ; p=.38)$.

After filling the Y-BOCS symptoms checklist, patients were specifically inquired about the content and form of the reported symptoms in order to ensure whether they were describing true clinically relevant obsessive-compulsive phenomena or other unrelated symptoms such as worries, depressive thoughts, or non-pathological behaviors. Whenever possible, external corroboration for the clinical data was obtained: in our study population, information from significant others was available in $46.7 \%$ of the cases. At the data collection, the interviewers were unaware of the final hypothesis of the study.

In order to classify patients with OCD, we employed a method that took into account the lifetime presence of checking and/ or washing compulsions, according to the Y-BOCS, and the clinical relevance of such symptoms, according to the clinical judgment of an experienced psychiatrist dedicated to the diagnosis and treatment of OCD (LFF). A symptom was deemed clinically relevant if it was associated with marked distress, was time-consuming, or significantly interfered with the patient's normal routine, occupational (or academic functioning), or usual social activities or relationships. According to this approach, each patient was included in one of the following groups: 1) OCD checkers (OCD-Ch), if at least one clinically significant checking compulsion was present in a patient without concomitant clinically significant washing compulsions during his/her lifetime $(n=20), 2)$ OCD washers (OCD-Wa), if at least one clinically significant washing or cleaning compulsion was present in a patient without concomitant clinically significant checking compulsions during his/her lifetime $(n=13)$, 3) OCD checkers and washers (OCD$\mathrm{CW}$ ), if at least one washing and one checking compulsions of clinical significance were present in a given patient during his/her lifetime ( $n=48)$; and 4) OCD non-checkers and nonwashers (OCD non-CW), if no clinically significant washing and checking compulsions were present in the same patient during his/her lifetime $(n=25)$.

\section{Statistical analysis}

The groups (OCD-Ch, OCD-Wa, OCD-WC, and OCD nonCW) were compared and contrasted using ANOVA followed by post-hoc Least Significant Difference (LSD) or Dunnett's tests (according to the homogeneity of variance) for continuous variables and the chi-square test followed by the partitioned chi-square test for categorical ones; Fisher's exact test was employed whenever indicated.

\section{Results}

The socio-demographic features, the clinical characteristics, and the patterns of psychiatric comorbidity of each subgroup are shown, respectively, in Tables 1 to 4 , along with the results of the statistical comparisons between the subgroups.

The results of vis-à-vis comparisons between subgroups are described bellow. Although some of these results were deemed more predictable, most were not.

OCD-Ch and OCD-Wa did not differ on most demographic and clinical features, the only exception being the number of different clinically significant obsessions, which was significantly higher in the former group (ANOVA, post-hoc LSD $p=.03$ ).

OCD-Wa were 1) more likely than the other groups to display ordering and symmetry compulsions (chi $=5.70$; $\mathrm{df}=1 ; \mathrm{p}=.02$ ) and 2 ) less likely than the other groups to exhibit obsessions with religious themes (chi $=4.64$; $\mathrm{df}=1$; $\mathrm{p}=.03$ ) and 3) major depressive disorder as a comorbidity (chi $=5.63 ; \mathrm{df}=1 ; \mathrm{p}=.01$ )

OCD-CW were more likely than the other groups 1) to exhibit an insidious onset of obsessive-compulsive symptoms (chi $=4.93 ; \mathrm{df}=1 ; \mathrm{p}=.02) ; 2$ ) to manifest itself as a mixed subtype of OCD (chi $=17.09 ; \mathrm{df}=1 ; \mathrm{p}<.0001)$;

Table 1 - Socio-demographic features of each OCD subgroup

\begin{tabular}{|c|c|c|c|c|c|}
\hline & OCD-Ch $(\mathrm{N}=20)$ & OCD-WA $(N=13)$ & OCD-CW $(\mathrm{N}=48)$ & OCD non-CW $(\mathrm{N}=25)$ & $\begin{array}{c}\text { P according to ANOVA or } \\
\times 2-\text { square test }\end{array}$ \\
\hline Age (in years) [ \pm SD] & $29.3 \pm 10.0$ & $37.62 \pm 15.3$ & $35.40 \pm 12.6$ & $33.5 \pm 14.7$ & NS \\
\hline$\%$ of female subjects & 40.0 & 69.2 & 62.5 & 45.8 & NS \\
\hline$\%$ of married subjects & 25.0 & 38.5 & 34.0 & 45.8 & NS \\
\hline $\begin{array}{l}\% \text { of economically active } \\
\text { subjects }\end{array}$ & 16.7 & 7.7 & 23.9 & 32.0 & NS \\
\hline$\%$ of Caucasian subjects & 78.9 & 92.3 & 85.1 & 72.0 & NS \\
\hline Educational levels & & & & & NS \\
\hline$\%$ Primary school (0-8 yr) & 31.6 & 15.4 & 13.0 & 12.5 & \\
\hline$\%$ High school (9-11 yr) & 15.8 & 46.2 & 45.7 & 37.5 & \\
\hline$\%$ College (> $12 \mathrm{yr}$ ) & 52.6 & 38.5 & 41.3 & 50.0 & \\
\hline
\end{tabular}

$O C D-C h=O C D$ checkers; $O C D-W A=O C D$ washers; $O C D-C W=O C D$ checkers and washers; $O C D$ non-CW = OCD non-checkers and non washers.

$S D=$ standard deviation 
Table 2 - Clinical characteristics of each OCD subgroup

\begin{tabular}{|c|c|c|c|c|c|}
\hline & OCD-Ch $(N=20)$ & OCD-WA $(N=13)$ & OCD-CW $(N=48)$ & OCD non-CW $(\mathrm{N}=25)$ & $\begin{array}{c}\text { P according to ANOVA or } \\
\times 2-\text { square test }\end{array}$ \\
\hline Age at onset (in years) [ \pm SD] & $16.4 \pm 10.0$ & $21.8 \pm 16.5$ & $19.4 \pm 12.9$ & $25.4 \pm 14.8$ & NS \\
\hline Type of onset & & & & & .03 \\
\hline$\%$ Insidious & 68.4 & 75.0 & $80.9^{*}$ & $48.0 \mathrm{tt}$ & \\
\hline$\%$ Acute & 31.6 & 25.0 & 19.1 & 52.0 & \\
\hline Duration (in years) $[ \pm \mathrm{SD}]$ & $12.9 \pm 8.8$ & $16.1 \pm 10.8$ & $15.5 \pm 10.5$ & $8.3 \pm 1.1 \neq \S \S$ & .03 \\
\hline Course & & & & & NS \\
\hline \% Chronic & 73.7 & 76.9 & 78.7 & 60.0 & \\
\hline \% Episodic & 26.3 & 23.1 & 21.3 & 40.0 & \\
\hline Type of OCD (ICD-10) & & & & & $<.001$ \\
\hline$\%$ Mixed & 80.0 & 61.5 & 95.8 & $48.0 t+t \S \S \S$ & \\
\hline$\%$ Other & 20.0 & 38.5 & 4.2 & 52.0 & \\
\hline Y-BOCS [ $=$ SD] & $24.1 \pm 8.4$ & $23.5 \pm 8.5$ & $27.8 \pm 6.2$ & $19.2 \pm 8.8$ §§§ & $<.001$ \\
\hline CGI $[ \pm$ SD] & $5.1 \pm 1.0$ & $5.3 \pm .8$ & $5.2 \pm 0.8$ & $5.0 \pm 1.0$ & NS \\
\hline HAM-D [ \pm SD] & $14.7 \pm 7.6$ & $13.1 \pm 5.6$ & $18.8 \pm 6.5$ & $16.9 \pm 6.5$ & NS \\
\hline BDI $[ \pm$ SD] & $16.6 \pm 7.9$ & $22.0 \pm 7.7$ & $25.9 \pm 8.1$ & $23.2 \pm 7.5$ & NS \\
\hline GAF [ \pm SD] & $52.4 \pm 7.5$ & $51.3 \pm 6.7$ & $51.9 \pm 6.8$ & $52.6 \pm 10.4$ & NS \\
\hline
\end{tabular}

OCD-CW vs. the other groups - * $P \leq .05$;

$O C D$ non- $C W$ vs. the other groups $-t P \leq .05 ; t+P \leq .01 ; t+t P \leq .001$;

$O C D$ non-CW vs. OCD-CW - $\neq P \leq .05$;

$O C D$ non-CW vs. $O C D-W a-\S \S P \leq .01 ; \S \S \S P \leq .001$;

$O C D-C h=O C D$ checkers; $O C D-W A=O C D$ washers; $O C D-C W=O C D$ checkers and washers; $O C D$ non-CW = OCD non-checkers and non washers; $I C D-10=T$ the Intemational Statistical Classification of Diseases and Related Health Problems, tenth edition; $Y-B O C S=Y a l e-B r o w n$ Obsessive-Compulsive Scale, BDI = the Beck Depression Inventory, HAM-D = the Hamilton Rating Scale for Depression, GAF = Global Assessment of Functioning. SD = standard deviation

Table 3 - Number and type of obsessive-compulsive symptoms in each OCD subgroup

\begin{tabular}{|c|c|c|c|c|c|}
\hline & OCD-Ch $(\mathrm{N}=20)$ & OCD-WA $(\mathrm{N}=13)$ & $\mathrm{OCD}-\mathrm{CW}(\mathrm{N}=48)$ & OCD non-CW $(\mathrm{N}=25)$ & $\begin{array}{c}\text { P according to ANOVA or } \\
\times 2-\text { square test }\end{array}$ \\
\hline No. of Obsessions & $3.1 \pm 2.0^{*}$ & $1.7 \pm 1.6$ & $3.1 \pm 1.8$ & $2.3 \pm 1.8$ & .04 \\
\hline Obsessive symptoms & & & & & NS \\
\hline$\%$ Aggressive & 75.0 & 46.2 & 70.8 & 83.3 & NS \\
\hline$\%$ Contamination & 50.0 & 61.5 & $72.9 \mathrm{ttt}$ & $8.3 \neq \neq \ddagger$ & $<.001$ \\
\hline$\%$ Sexual & 35.0 & .0 & 16.7 & 25.0 & NS \\
\hline$\%$ Religious & 25.0 & $.0 \S$ & 20.8 & $41.7 \ddagger$ & .03 \\
\hline$\%$ Somatic & 45.0 & 7.7 & 25.0 & 16.7 & NS \\
\hline$\%$ Symmetry & 25.0 & 23.1 & 27.1 & 4.2 & NS \\
\hline$\%$ Hoarding & 12.5 & .0 & .0 & 12.5 & NS \\
\hline$\%$ Miscellaneous & 55.0 & 30.8 & 47.9 & 50.0 & NS \\
\hline Compulsive symptoms & & & & & NS \\
\hline$\%$ Repeating rituals & 45.0 & 38.5 & 58.3 & 29.2 & NS \\
\hline$\%$ Ordering & 20.0 & $46.2 \S$ & 27.1 & $.0 \neq \neq$ & .007 \\
\hline$\%$ Counting & 25.0 & 23.1 & 18.8 & 12.5 & NS \\
\hline$\%$ Hoarding & 5.0 & 15.4 & 18.8 & 12.5 & NS \\
\hline$\%$ Miscellaneous & 45.0 & 15.4 & 37.5 & 41.7 & NS \\
\hline
\end{tabular}

$O C D-C h$ vs. OCD $-W a-* P \leq .05$

$O C D C W$ vs. the other groups - $t+P \leq .001$

$O C D$ non-CW vs. the other groups $-\ddagger P \leq .05 ; \neq ¥ P \leq .01 ; \ddagger \neq \mp \leq .001$;

$O C D$-Wa vs. the other groups $-\S P \leq .05$ :

$O C D-C h=O C D$ checkers; $O C D-W A=O C D$ washers; $O C D-C W=O C D$ checkers and washers; $O C D$ non- $C W=O C D$ non-checkers and non washers

and 3) to display obsessions with contamination themes (chi $=14.95 ; \mathrm{df}=1 ; \mathrm{p}<.0001)$. As expected, OCD-CW exhibited significantly higher number of different clinically significant compulsions than OCD-Ch (ANOVA, post-hoc LSD $p=.001$ ), OCD-Wa (ANOVA, post-hoc LSD $p=.004$ ), and OCD non-CW (ANOVA, post-hoc LSD $p<.001$ ).

OCD non-CW were significantly more likely than the other groups (1) to exhibit an acute onset of obsessive-compulsive symptoms (chi $=7.53 ; \mathrm{df}=1 ; \mathrm{p}=.006$ ), and (2) to exhibit obsessions with religious themes ( $\mathrm{chi}=5.47$; df $=1$; $\mathrm{p}=.02$ ), but significantly less likely than the other groups

(3) to manifest itself as a mixed subtype of OCD (chi=16.10; $\mathrm{df}=1 ; \mathrm{p}<.0001)$; and (4) to display obsessions with contamination themes ( $\mathrm{chi}=24.20 ; \mathrm{df}=1 ; \mathrm{p}<.0001)$, as well as (5) ordering and symmetry compulsions (chi = 8.73; $\mathrm{df}=1 ; \mathrm{p}=.003)$. OCD non-CW also exhibited (6) a shorter duration of illness than OCD-CW (ANOVA, post-hoc LSD $p=.006$ ) and OCD-Wa (ANOVA, post-hoc LSD $p=.03$ ), (7) a less severe intensity of obsessive-compulsive symptoms than the OC-CW (ANOVA, Dunnett's test $p<.0001$ ), and, as expected (8) a lower number of different clinically significant compulsions than OCD-Ch (ANOVA, post-hoc LSD $p<.001$ ), OCD-Wa (ANOVA, post-hoc LSD $p=.003$ ), and OCD-CW (ANOVA, post-hoc LSD $p<.001$ ). A trend to display (9) higher rates of episodic OCD was also found among OCD non-CW (chi $=2.86 ; \mathrm{df}=1 ; \mathrm{p}=.09$ ). 
Table 4 - Patterns of psychiatric comorbidity of each OCD subgroup

\begin{tabular}{|c|c|c|c|c|c|}
\hline & OCD-Ch $(\mathrm{N}=20)$ & OCD-WA $(N=13)$ & OCD-CW $(\mathrm{N}=48)$ & OCD non-CW $(\mathrm{N}=25)$ & $\begin{array}{c}\text { P according to ANOVA or } \\
\times 2-\text { square test }\end{array}$ \\
\hline No. of comorbid disorders & $1.8 \pm 1.0$ & $1.4 \pm 1.3$ & $1.9 \pm 1.4$ & $1.4 \pm 1.0$ & NS \\
\hline$\%$ Any mood disorder & 50.0 & 41.7 & 74.5 & 72.0 & NS \\
\hline$\%$ Major depressive disorder & 44.4 & $25.0^{\circ}$ & 63.8 & 68.0 & .04 \\
\hline$\%$ Dysthymia & 11.1 & 16.7 & 23.4 & 12.0 & NS \\
\hline \% Bipolar II & .0 & .0 & 4.3 & 0.0 & NS \\
\hline$\%$ Cyclothymia & .0 & .0 & 2.1 & 0.0 & NS \\
\hline$\%$ Any anxiety disorder & 33.3 & 8.3 & 29.8 & 24.0 & NS \\
\hline$\%$ Panic disorder & 22.2 & 8.3 & 12.8 & 20.0 & NS \\
\hline$\%$ Agoraphobia & 11.1 & .0 & 4.3 & 16.0 & NS \\
\hline \% Social phobia & 11.1 & 8.3 & 14.9 & 12.0 & NS \\
\hline$\%$ Specific phobia & .0 & 8.3 & 6.4 & 4.0 & NS \\
\hline$\%$ PTSD & 5.6 & .0 & .0 & 0.0 & NS \\
\hline$\%$ GAD & 11.1 & 16.7 & 6.4 & 4.0 & NS \\
\hline$\%$ Any eating disorder & 5.6 & .0 & 14.9 & 8.0 & NS \\
\hline$\%$ Binge eating disorder & 5.3 & .0 & 8.3 & 8.0 & NS \\
\hline \% Bulimia nervosa & .0 & .0 & 4.2 & 0.0 & NS \\
\hline$\%$ Anorexia nervosa & .0 & .0 & 2.1 & 0.0 & NS \\
\hline$\%$ Tic disorders & 22.2 & 25.0 & 8.5 & 4.0 & NS \\
\hline $\begin{array}{l}\text { \% Impulse-control disorders } \\
\text { not elsewhere classified }\end{array}$ & 11.1 & .0 & 21.3 & 8.0 & NS \\
\hline
\end{tabular}

OCD-Wa vs. the other groups: ${ }^{*} P \leq .05$;

$O C D-C h=O C D$ checkers; $O C D-W A=O C D$ washers; $O C D-C W=O C D$ checkers and washers; $O C D$ non-CW = OCD non-checkers and non washers

Discussion

We investigated the utility of washing and checking compulsions as markers of valid subtypes of OCD. To reach this goal, we evaluated the socio-demographic features, the clinical characteristics, and the patterns of psychiatric comorbidity of 106 patients with OCD seen at the Anxiety and Depression Research Program of the Institute of Psychiatry of the Universidade Federal do Rio de Janeiro.

Our first hypothesis, i.e., that OCD-Ch and OCD-Wa would be distinguishable from each other on socio-demographic grounds, was not supported. In fact, this negative finding dovetails with those of most previous vis-à-vis studies comparing these potential subtypes. ${ }^{14,22}$ Only Khanna et al described a distinctive pattern of chronological age, marital status, gender, religion, and mode of onset among OCD checkers and washers. ${ }^{21}$ However, as they employed the ICD-9 criteria, which do not allow the diagnosis of OCD in patients with 'endogenous depression', it is possible that their sample was artificially free from the effect of this comorbidity. This is a significant limitation, since it was already demonstrated that up to $67 \%$ of patients with OCD have a lifetime history of major depression ${ }^{39}$ and the coexistence of both disorders is associated with more severe forms of OCD. ${ }^{40}$

In terms of clinical presentation, OCD-Ch and OCD-Wa were also almost undistinguishable. The only significant phenomenological difference between OCD-Ch and OCD-Wa was the number of different types of obsessions, which was significantly higher among the former subgroup. Similar findings were already described in other studies, suggesting that checking behavior is more pervasive and unspecific, and may develop in response to different types of obsessions. Indeed, in a recent review paper of twelve principal-components and confirmatory factor analytic studies involving over 2,000 patients with OCD, one of the four symptom dimensions most consistently extracted was the 'obsessions/checking' dimension. ${ }^{41}$

The lack of many significant differences between these subgroups may have resulted from the lifetime symptom rating method adopted by us and others. ${ }^{22}$ It is conceivable that, due to the cross-sectional method of classification chosen by most previous research groups, some of the differences described by clinical, ${ }^{14}$ cognitive, ${ }^{19}$ neuroimaging, ${ }^{23-24}$ and treatment response ${ }^{25-28}$ studies may be actually state-related findings associated with the presence of checking and/or washing compulsions.

Matsunaga et $\mathrm{al}^{22}$ suggested that the OCD-CW may constitute a more valid subtype of OCD. In their study, this combined group had a poorer level of insight into OCD symptoms, more severe perfectionism and depressive symptoms, higher rates of lifetime impulsive behaviors, increased prevalence of schizotypal and borderline personality disorders, and lower scores on the Global Assessment of Functioning Scale. In contrast, we found that the OCD-CW group was more likely to exhibit an insidious onset of obsessive-compulsive symptoms, to manifest itself as a mixed subtype of OCD (i.e., with both obsessions and compulsions) and to display obsessions with contamination themes. Given these relatively few (and, to a certain extent, unremarkable) particularities of the OCD-CW in our study, we feel that the validity of this subgroup of patients should be further probed in future studies with larger samples of OCD patients.

On the other hand, more striking peculiarities were found among the group of OCD patients without both checking and washing compulsions (OCD non-CW). These patients were more likely to exhibit an acute onset, a shorter duration of illness, obsessions with religious themes, an episodic course (trend) and less severe obsessive-compulsive symptoms. This subtype of OCD was also less likely to manifest itself as a mixed subtype of OCD and to display contamination obsessions as well as ordering or symmetry compulsions. This potential subtype of OCD may overlap with a frequent compulsive-free factor (including religious and sexual obsessions) identified in seven out of twelve principal-components and confirmatory factor analytic studies reviewed by Mataix-cols et al. ${ }^{41}$

Some previous studies have already associated checking and washing behaviors with other putative subtypes of OCD.42-46 Nevertheless, these positive findings remain disputable..$^{5-6,47-48}$ 
For example, checking compulsions were reported to be more common among patients with early-onset ${ }^{42}$ and tic-related ${ }^{43}$ subtypes, while washing compulsions were found to predominate among late-onset ${ }^{42}$ and tic-free ${ }^{44-46}$ OCD patients. We were unable to find any association between these types of compulsions and features previously known to possibly subtype OCD, such as those based on gender, age at onset, and patterns of comorbidity.

Our study has several limitations. Firstly, although we have assessed more than one hundred cases of OCD, a few number of patients were classified as OCD-Ch $(n=20)$ and OCD-Wa $(n=13)$. Secondly, many potential phenomenological and neurobiological differences between the groups, such as levels of insight ${ }^{22}$ or brain functioning parameters ${ }^{23}$ were not investigated, making the conclusions of our report preliminary. Thirdly, it could be argued that relying on the patients' memory of suffering or impairment associated with a past behavior to infer clinical relevance of a given symptom may introduce a significant recall bias. We acknowledged this limitation and tried to keep it off by confirming the patients' report with significant others whenever possible (unfortunately, that type of collateral information was available in less than half of the sample).

Finally, the use of multiple statistical comparisons represents another potential drawback of our study. It may be argued that a procedure such as Bonferroni correction should be employed in order to minimize type I statistical errors, even at the cost of eliminating the statistical significance of some of our findings. However, given the incipient state of the currently available knowledge on the checking vs. washing issue, we felt it would be counter-productive to discard preliminarily some correlations that might be further investigated in future studies. ${ }^{49}$

\section{Conclusion}

We were unable to find any significant difference between checkers and washers in a sample of patients with OCD, thus supporting the results of a recent study employing a similar investigation method. ${ }^{22}$ Nevertheless, our findings were consistent with the existence of a subtype of OCD characterized by the absence of both types of compulsions. Taken together, our results point to the utility of checking or washing compulsions as markers of valid subtypes of OCD.

\section{Acknowledgments}

This work was supported by a grant from Conselho Nacional de Desenvolvimento Científico e Tecnológico (CNPq).

\section{References}

1. Bogetto F, Venturello S, Albert U, Maina G, Ravizza L. Genderrelated clinical differences in obsessive-compulsive disorder. Eur Psychiatry. 1999;14(8):434-41.

2. Lensi P, Cassano GB, Correddu G, Ravagli S, Kunovac JL, Akiskal HS. Obsessive-compulsive disorder. Familial-developmental history, symptomatology, comorbidity and course with special reference to gender-related differences. Br J Psychiatry. 1996;169(1):101-7.

3. Fontenelle L, Marques C, Versiani M. The effect of gender on the clinical features and therapeutic response in obsessive-compulsive disorder. Rev Bras Psiquiatr. 2002;24(1):7-11.

4. Sobin C, Blundell ML, Karayiorgou M. Phenotypic differences in early- and late-onset obsessive-compulsive disorder. Compr Psychiatry. 2000;41(5):373-9.

5. Rosario-Campos MC, Leckman JF, Mercadante MT, Shavitt RG, Prado HS, Sada P, et al. Adults with early-onset obsessive-compulsive disorder. Am J Psychiatry. 2001;158(11):1899-903.
6. Fontenelle LF, Mendlowicz MV, Marques C, Versiani M. Early- and late- onset obsessive-compulsive disorder in adult patients: an exploratory clinical and therapeutic study. J Psychiatr Res. 2003;37(2):127-33. Erratum in: J Psychiatr Res. 2003;37(3):263.

7. Nestadt G, Addington A, Samuels J, Liang KY, Bienvenu OJ, Riddle $M$, et al. The identification of OCD-related subgroups based on comorbidity. Biol Psychiatry. 2003;53(10):914-20.

8. Albert U, Maina G, Ravizza L, Bogetto F. An exploratory study on obsessive-compulsive disorder with and without a familial component: are there any phenomenological differences? Psychopathology. 2002;35(1):8-16.

9. Jenike MA, Baer L, Minichiello WE, Rauch SL, Buttolph ML. Placebocontrolled trial of fluoxetine and phenelzine for obsessive-compulsive disorder. Am J Psychiatry. 1997;154(9):1261-4.

10. McDougle CJ, Goodman WK, Leckman JF, Lee NC, Heninger GR, Price LH. Haloperidol addition in fluvoxamine-refractory obsessivecompulsive disorder. A double-blind, placebo-controlled study in patients with and without tics. Arch Gen Psychiatry. 1994;51(4):302-8.

11. Swedo SE, Leonard HL, Garvey M, Mittleman B, Allen AJ, Perlmutter $\mathrm{S}$, et al. Pediatric autoimmune neuropsychiatric disorders associated with streptococcal infections: clinical description of the first 50 cases. Am J Psychiatry. 1998;155(2):264-71.

12. Hounie AG, Brotto AS, Diniz J, Chacon PJ, Miguel EC. Transtorno obsessivo-compulsivo: possíveis subtipos. Rev Bras Psiquiatr. 2001;23(Supl 2):13-6.

13. Fontenelle LF, Mendlowicz MV, Marques C, Versiani M. Trans-cultural aspects of obsessive-compulsive disorder: a description of a Brazilian sample and a systematic review of international clinical studies. J Psychiatr Res. 2004;38(4):403-11.

14. Steketee GS, Grayson JB, Foa EB. Obsessive-compulsive disorder: differences between washers and checkers. Behav Res Ther. 1985;23(2): 197-201.

15. Foa EB, Huppert JD, Leiberg S, Langner R, Kichic R, Hajcak G, et al. The Obsessive-Compulsive Inventory: development and validation of a short version. Psychol Assess. 2002;14(4):485-96.

16. Leckman JF, Grice DE, Boardman J, Zhang H, Vitale A, Bondi C, et al. Symptoms of obsessive-compulsive disorder. Am J Psychiatry. 1997;154(7):911-7.

17. Summerfeldt LJ, Richter MA, Antony MM, Swinson RP. Symptom structure in obsessive-compulsive disorder: a confirmatory factoranalytic study. Behav Res Ther. 1999;37(4):297-311.

18. Calamari JE, Wiegartz PS, Janeck AS. Obsessive-compulsive disorder subgroups: a symptom-based clustering approach. Behav Res Ther. 1999;37(2):113-25.

19. Ceschi G, Van der Linden M, Dunker D, Perroud A, Bredart S. Further exploration memory bias in compulsive washers. Behav Res Ther. 2003;41(6):737-48.

20. Horesh N, Dolberg OT, Kirschenbaum-Aviner N, Kotler M. Personality differences between obsessive-compulsive disorder subtypes: washers versus checkers. Psychiatry Res. 1997;71(3)197-200.

21. Khanna S, Mukherjee D. Checkers and washers: valid subtypes of obsessive compulsive disorder. Psychopathology. $1992 ; 25(5): 283-8$.

22. Matsunaga H, Kiriike N, Matsui T, Iwasaki Y, Koshimune K, Ohya K, et al. A comparative study of clinical features between pure checkers and pure washers categorized using a lifetime symptom rating method. Psychiatry Res. 2001;105(3):221-9.

23. Phillips ML, Marks IM, Senior C, Lythgoe D, O'Dwyer AM, Meehan $O$, et al. A differential neural response in obsessive-compulsive disorder patients with washing compared with checking symptoms to disgust. Psychol Med. 2000;30(5):1037-50.

24. Rauch SL, Dougherty DD, Shin LM, Alpert NM, Manzo P, Leahy L, et al. Neural correlated of factor-analyzed OCD symptom dimensions: a PET study. CNS Spectrums. 1998;3:37-48.

25. Alarcon RD, Libb JW, Spitler D. A predictive study of obsessivecompulsive disorder response to clomipramine. J Clin Psychopharmacol. 1993;13(3):210-3.

26. Ravizza L, Barzega G, Bellino S, Bogetto F, Maina G. Predictors of drug treatment response in obsessive-compulsive disorder. J Clin Psychiatry. 1995;56(8):368-73. 
27. Basoglu M, Lax T, Kasvikis Y, Marks IM. Predictors of improvement in obsessive-compulsive disorder. J Anxiety Disord. 1988;2:299317.

28. Buchanan AW, Meng KS, Marks IM. What predicts improvement and compliance during the behavioral treatment of obsessive compulsive disorder? Anxiety. 1996;2(1):22-7.

29. Drummond LM. The treatment of severe, chronic, resistant obsessivecompulsive disorder. An evaluation of an in-patient programme using behavioural psychotherapy in combination with other treatments. Br J Psychiatry. 1993;163:223-9.

30. Rettew DC, Swedo SE, Leonard HL, Lenane MC, Rapoport JL. Obsessions and compulsions across time in 79 children and adolescents with obsessive-compulsive disorder. J Am Acad Child Adolesc Psychiatry. 1992;31(6):1050-6.

31. First MB, Spitzer RL, Gibbon M, Williams JBW. Structured Clinical Interview for DSM-IV Axis I Disorders, Research Version, Patient Edition (SCID-I/P) New York: Biometrics Research, New York State Psychiatric Institute; 1997.

32. World Health Organization. The ICD-10 Classification of Mental and Behavioural Disorders. Clinical Descriptions and Diagnostic Guidelines. Geneva: World Health Organization; 1993.

33. Goodman WK, Price LH, Rasmussen SA, Mazure C, Fleischmann RL, Hill CL, et al. The Yale-Brown Obsessive Compulsive Scale. I. Development, use, and reliability. Arch Gen Psychiatry. 1989;46(11):1006-11.

34. Goodman WK, Price LH, Rasmussen SA, Mazure C, Delgado P, Heninger GR, et al. The Yale-Brown Obsessive Compulsive Scale. II. Validity. Arch Gen Psychiatry. 1989;46(11):1012-6.

35. Guy W. ECDEU Assessment manual for psychopharmacology. Rockville: US Department of Health, Education and Welfare Publication-ADM; 1976.

36. Hamilton M. Development of a rating scale for primary depressive illness. Br J Soc Clin Psychol. 1967;6(4):278-96.

37. Gorenstein C, Andrade L, Vieira Filho AH, Tung TC, Artes R. Psychometric properties of the Portuguese version of the Beck Depression Inventory on Brazilian college students. J Clin Psychol. 1999;55(5):553-62.

38. American Psychiatric Association. Diagnostic and Statistical Manual of Mental Disorders, $4^{\text {th }}$ edition. Washington, American Psychiatric Association; 1994.

39. Rasmussen SA, Eisen JL. Clinical and epidemiologic findings of significance to neuropharmacological trials in OCD. Psychopharmacol Bull. 1988;24(3):466-70.

40. Perugi G, Akiskal HS, Pfanner C, Presta S, Gemignani A, Milanfranchi $A$, et al. The clinical impact of bipolar and unipolar affective comorbidity on obsessive-compulsive disorder. J Affect Disord. 1997;46(1): 15-23.

41. Mataix-Cols D, Rosario-Campos MC, Leckman JF. A multidimensional model of obsessive-compulsive disorder. Am J Psychiatry. 2005; 162(2):228-38.

42. Noshirvani HF, Kasvikis Y, Marks IM, Tsakiris F, Monteiro WO. Genderdivergent aetiological factors in obsessive-compulsive disorder. $\mathrm{Br} \mathrm{J}$ Psychiatry. 1991;158:260-3.

43. Leckman JF, Grice DE, Barr LC, de Vries AL, Martin C, Cohen DJ, et al. Tic-related vs. non-tic-related obsessive compulsive disorder. Anxiety. 1994;1(5):208-15.

44. Hanna GL, Piacentini J, Cantwell DP, Fischer DJ, Himle JA, Van Etten M. Obsessive-compulsive disorder with and without tics in a clinical sample of children and adolescents. Depress Anxiety. 2002; 16(2):59-63.

45. Holzer JC, Goodman WK, McDougle CJ, Baer L, Boyarsky BK, Leckman JF, et al. Obsessive-compulsive disorder with and without a chronic tic disorder. A comparison of symptoms in 70 patients. $\mathrm{Br}$ J Psychiatry. 1994;164(4):469-73.

46. George MS, Trimble MR, Ring HA, Sallee FR, Robertson MM. Obsessions in obsessive-compulsive disorder with and without Gilles de la Tourette's syndrome. Am J Psychiatry. 1993;150(1):93-7.

47. Millet B, Kochman F, Gallarda T, Krebs MO, Demonfaucon F, Barrot I, et al. Phenomenological and comorbid features associated in obsessive-compulsive disorder: influence of age of onset. J Affect Disord. 2004;79(1-3):241-6.
48. Petter T, Richter MA, Sandor P. Clinical features distinguishing patients with Tourette's syndrome and obsessive-compulsive disorder from patients with obsessive-compulsive disorder without tics. J Clin Psychiatry. 1998;59(9):456-9.

49. Rothman KJ. No adjustments are needed for multiple comparisons. Epidemiology. 1990;1(1):43-6. 